Борис Норман

Белорусский государственный университет, Минск

Кафедра теоретического и славянского языкознания

Уральский федеральный университет имени первого Президента России Б.Н. Ельцина, Екатеринбург

Проблемная лаборатория компьютерной лексикографии boris.norman@gmail.com
УДК 81'27'36

https://doi.org/10.18485/slavistika.2018.22.1.7 оригинални научни рад примљено 08.02.2018.

прихваћено за штампу 17.05.2018.

\title{
ГРАММАТИКАЛИЗАЦИЯ ЯЗЫКОВОЙ ЕДИНИЦЫ И СФЕРА ДЕЙСТВИЯ КОГНИТИВНЫХ ПРОЦЕССОВ
}

Статья анализирует процессы грамматикализации в славянских языках. Рассматриваются формы ренарративного наклонения в болгарском и их соответствия в русском, словообразовательные модели с префиксом над- в болгарском и с префиксом nad- в польском, выражение итеративности в русском и чешском языках и др. Делается вывод о связи когнитивного процесса категоризации с явлением грамматикализации.

Ключевые слова: грамматикализация, славянские языки, словообразовательная модель, префикс, когнитивная сфера, категоризация.

The article analyzes the process of grammaticalization in Slavic languages. Forms of the renarrative mood in Bulgarian and their Russian equivalents, word-building patterns with the над- prefix in Bulgarian and nad-prefix in Polish, expression of iterativity in Russian and Czech etc. are considered. The conclusion reached points to the existence of connections between the cognitive process of categorization and the phenomenon of grammaticalization.

Keywords: grammaticalization, Slavic languages, word-building patterns, prefix, cognitive sphere, categorization

Действительность, отражаясь в сознании социума в виде многообразных ментальных единиц - ощущений, впечатлений, представлений, гештальтов, образов, фреймов, - закрепляется там с помощью различных языковых средств. В совокупности своей эти средства образуют пусть неполную и фрагментарную, но оригинальную языковую картину мира. Важнейшее свойство последней стабильность: «в этом ее суть и предназначение - сохранять и из поколения в поколение воспроизводить упрощенное, обиходное структурирование окружающего мира, обеспечивать преемственность языкового мышления носителей данного языка традиционно сложившимися категориями» (Корнилов 2003: 19). При этом не подлежит сомнению, что функционирование языка обеспечивается взаимодействием разных типов значений, из которых наиболее известные, можно сказать, общепринятые, - значения лексические и грамматические, различающиеся по целому ряду признаков.

Одним из трендов современной лингвистики как раз и является изучение динамики семантических явлений, а точнее - изменяющегося статуса содержательных языковых единиц и целых категорий. Феноменам грамматикализации и лексикализации посвящены уже десятки статей, монографий и научных сборников. Среди авторов этих работ - известные лингвисты: Т. Гивон, Б. Хайне,

* Исследование выполнено за счет гранта Российского научного фонда (проект № 1618-02005). 
М. Хаспельмат, Дж. Байби, К. Леманн, Т.А. Майсак и др. Данные процессы понимаются как эволюционное движение от одного условного полюса к другому. Можно считать, что чем регулярнее и обязательнее связь ментального отражения с языковым выражением, тем это выражение в принципе больше относится к ведомству грамматики.

В частности, Дж. Байби определяет грамматикализацию как «процесс, при котором лексические единицы или последовательности единиц становятся грамматической морфемой, меняя при этом свою дистрибуцию и функцию в общении» (Bybee 2003: 146). В основе такой метаморфозы лежит автоматизация речевых навыков и два ее психологических спутника - хабитуация (привыкание к часто повторяемому) и эмансипация (освобождение от предыдущего опыта).

По мнению К. Леманна, «грамматикализация языкового знака - процесс, в ходе которого знак теряет свою автономность, становясь в большей степени подверженным ограничениям языковой системы» (Lehmann 2005: 155). Определение немецкого автора отличается, как мы видим, более общим характером, оно не привязывает грамматикализацию к каким-то конкретным языковым единицам.

К настоящему моменту, можно считать, выявлены основные типологические признаки данного процесса, применимые к материалу различных языков; предложены универсальные параметры грамматикализации. В частности, в работе упомянутого выше К. Леманна предложены 3 критерия грамматикализованности языковой единицы: вес, когезия и вариативность, которые действуют в парадигматической и синтагматической плоскостях языка и воплощаются в шести параметрах. А именно: среди парадигматических параметров выделяются целостность, парадигматичность и парадигматическая вариативность, а среди синтагматических - сфера действия, связанность, синтагматическая вариативность. Они довольно сложным образом взаимодействуют между собой (Lehmann 2002: 143-150). Реализация того или иного параметра зависит и от общей типологической структуры языка.

Если применять понятие грамматикализации к привычным языковым единицам, то повышающаяся «степень грамматичности» может охватывать и факты словоизменения, и словообразовательные явления, и синтаксические конструкции.

В настоящей статье мы обратим внимание на некоторые факты словоизменения и словообразования современных славянских языков.

Начнем с проблемы объективности передаваемого при общении смысла, то есть его истинности и безотносительности к личностям коммуникантов. Информация, содержащаяся в языковых единицах, может быть никак не маркирована в том, что касается ее источника, и в том, какое отношение к ней имеет сам говорящий. В редких случаях говорящий может указать на источник этой информации (например: «Петя сказал, что...», «По словам твоей мамы...», «Я прочитал в Интернете, будто...» и т.п.) или же дистанцироваться от нее («Я сам не видел, но говорят, что...» и т.п.). Verba dicendi, конечно, - самые бесспорные средства ввода чужой речи. Существуют в русском языке и дискурсивные слова, в обязанности которых входит указание на имперцептивный характер 
сообщений: это частицы якобы, мол, будто, дескать (-де), грит («говорит»). Приведем два примера, в которых данный смысл специально подчеркивается: первый из них представляет собой фрагмент народной песни, а второй - юмористическую репризу.

$$
\begin{aligned}
& \text { В лесу, говорят, в бору, говорят, } \\
& \text { Растет, говорят, сосёнка... }
\end{aligned}
$$

Говорит одно, пишет третье, думает второе. Вслух «нет», в урну «да». Поддержать шефа, отрицая и поддерживая, свалить, набрать очки, нахваливая конкурента. Хотя и дескать, якобы и мол (М. Жванецкий. Время для умных).

Понятно, что в обоих приведенных случаях маркеры «неочевидности» используются как художественное средство (о первом из них Т. В. Цивьян прямо говорит: стилистический прием - Цивьян 2005: 164). В целом же это ситуация для русского языка довольно редкая, и считать показатели мол, дескать, грит и т. п. грамматикализованными невозможно; «частицы останавливаются на последнем шаге: переход клитики в морфему не происходит» (Копотев 2011: 735).

В то же время существуют языки, в которых обозначение неочевидности ситуации, или, что то же самое, «несвидетельского отношения» к информации, выражается с высокой степенью обязательности и регулярности. Одним из таких языков является современный болгарский. В его грамматике принято выделять так называемое пересказывательное наклонение (по-другому, имперцептив, ренарратив, конклюзив, эвиденциал, адмиратив и т.д.), которое, с учетом его морфологической парадигмы, считают особым, «экзотическим» на славянском фоне, видом модальности (Куцаров 1994). Формы этого наклонения употребляются обычно тогда, когда говорящий излагает чужое мнение, более того - сомневается в его истинности и желает от него дистанцироваться, отстраниться. Существуют болгарские фольклорные и литературные жанры, тексты которых строятся целиком в пересказывательном наклонении. Это сказки, предания, басни, анекдоты, исторические описания и т.п. Семантика «неочевидности» легко перерастает в сомнение, удивление, недоверие и, далее, в возмущение или восхищение. Это хорошо сочетается с таким этнопсихологическим качеством, как недоверчивость (нередко в комплекте с иронией или негативной реакцией), составляющим важную черту болгарского менталитета (Норман 2005: 56-59; Ковш 2007: 13). Понятно, что картина мира в сознании носителей болгарского и русского языков, при более или менее единой референтной составляющей, будет в данном фрагменте заметно различаться, и, соответственно, набор их речеповеденческих тактик тоже будет неодинаковым. Вот как пишет болгарский автор: «Для русского языка оппозиция пересказывание/непересказывание гораздо менее релевантна, чем для болгарского. Выражение пересказывания в русском языке можно представить шкалой, в одном конце которой находятся случаи, когда оно вообще не выражено, а в другом - глаголы речи, отглагольные существительные, подсказывающие, что следует чужая речь, и модальные частицы мол, дескать, будто, будто бы» (Васева 2005: 30).

Проанализируем с этой точки зрения повесть болгарского писателя Йордана Радичкова (1929-2004) «Таралеж» и ее перевод на русский язык под названием «Еж» (переводчик - М. Михелевич). Радичков - одна из наиболее замет- 
ных фигур в новейшей болгарской литературе. Дважды номинировался на Нобелевскую премию по литературе; известен главным образом благодаря своей склонности к литературным парадоксам и фантасмагории. В центре повести «Таралеж» - приключения любознательного ежика, любителя лягушачьих концертов. А в качестве второстепенных персонажей здесь фигурируют и известный болгарский писатель Эмилиан Станев с его собакой, и французские старушки-путешественницы, любительницы гашиша, и матерый контрабандист, больной проказой, и монах, наблюдающий за купающейся женщиной, и даже дьявол на фоне ада и рая... Весь этот балаган пронизан чувством симпатии, легкой иронии и того, что нынче называют стёбом.

Важно, что все повествование строится в обычном изъявительном наклонении (преимущественно в глагольных временах аориста и имперфекта). И даже там, где рассказчик, казалось бы, имел право усомниться в передаваемой информации - например, при описании привычек еще одного персонажа - кухонной «тараканихи» или при передаче чьего-то мнения о вреде курения и кофе, обо всем этом говорится как о вполне достоверных событиях. Иными словами, писатель предлагает нам принять весь сконструированный им мир за реальную жизнь. Прямая речь персонажей вводится соответствующими словами автора: промърмори 'пробормотал', възкликна 'воскликнул', попита 'спросил', вдигна рамене 'пожал плечами', пищеше 'кричала', въодушеви се 'воодушевился' и т.п.

Но в четырех местах повести автор прибегает к формам пересказывательного наклонения. Это передача впечатлений автолюбителя-шведа, машина которого наехала на ежа (перечисляется десяток действий: видял съвсем близо до банкета нещз като кълбо; той само закачил кълбото; гумата изгърмяла; той загубил управлението и т.п.), признания акцизных, продавшихся контрабандистам (и здесь используется десяток форм пересказывательного наклонения: как водили ръкопашен бой с тях, но ония били многочислени, вързали ги, напъхали им кърпи в устата и т.п.), объяснения старушек-француженок (смятали да закусят в София; не успели да го разгледат съвсем добре и т.п.) и рассказ Эмилиана Станева о собаке Глене (кучето не било във форма, яло голям бой, стопанинът му се принудил да се завре във фиищата и т.п.). Все эти четыре фрагмента маркированы для болгарского читателя «несвидетельской» модальностью.

Что же касается русского перевода, то в первом из указанных отрывков несвидетельский характер информации передан одной словоформой говорит и одной частицей мол; в последнем из четырех фрагментов только один раз употреблено мол. В остальных фрагментах читатель вообще не получает никаких сигналов особой дистанцированности рассказчика от событий. Все они изложены в точно таком же ключе, как и остальной текст повести.

Проведенный анализ подтверждает, что для русского читателя степень правдоподобия или, наоборот, невероятности ситуаций не имеет такого значения, как для болгарского. И можно согласиться с цитированной выше И. Васевой еще в одном пункте: «При переводе с русского на болгарский, как правило, текст обогащается; при переводе в болгарского на русский, наоборот, он теряет некоторые оттенки (несущественные для русского)...» (Там же: 32). Впрочем, применительно к пересказывательному наклонению это закономерность, касающаяся не только русского языка. Другой болгарский исследователь, М. Виденов, 
замечает: «Нас удивляет, что $80 \%$ наших имперцептивных форм переводчики на другие языки передают обычными формами изъявительного наклонения без обстоятельственных пояснений, хотя рассказчик не является свидетелем событий. У другого народа - другие ориентиры и другое языковое отношение к свидетельству и несвидетельству или сомнению» (Виденов 1994: 48).

Принимая эту точку зрения, мы тем самым утверждаем, что процесс грамматикализации языковых единиц не только меняет в какой-то части типологическую характеристику языка, но и служит средством организации специфической картины мира соответствующего социума.

Пересказывательное наклонение в болгарском - несомненно грамматическая категория, хотя в текстах эти формы используются не всегда последовательно, и пособия по стилистике то и дело обращают внимание читателей на смешение ренарратива, конклузива и индикатива (Чакърова и др. 1999: 132-133 и др.). Но процесс грамматикализации может дойти и до менее отчетливой стадии, а результат его в таком случае принимает вид, скажем, словообразовательной модели. Обратимся к другой ситуации, опять-таки на сопоставительном материале русского и болгарского языков.

В своем стремлении к совершенству люди пытаются превзойти друг друга по тем или иным показателям (условно такую ситуацию можно обозначить как «кто кого»). Данный феномен актуализируется в сознании человека, вычленяется в отдельное понятие и закрепляется в соответствующих номинациях (ср. в русском языке существительные соревнование, состязание, конкурс, первенство, чемпионат, соперничество и т.п., глаголы обыграть, выцграть, победить, побороть, обогнать и т.п.). Словари русского языка фиксируют и многочисленные лексемы, обозначающие частные виды соперничества или состязания. В том числе такое значение обнаруживается и у многозначного префикса пере-: перекричать кого, пересидеть кого, переесть кого, перепить кого, переговорить кого и т. д. (Ожегов 1988). Обязательным условием реализации данных значений является наличие при глаголе прямого дополнения, обозначающего соперника, контрагента. Вместе с тем, не случайно в большинстве случаев при этих глаголах дается помета разг. или прост.: они характеризуются той или иной степенью потенциальности или окказиональности. Это значит, что в конкретной ситуации, сводящей к минимуму словообразовательные запреты, мы легко можем образовать соответствующий глагол - сказать: кто кого перемолчит, переглядит, перетаниует, переврет... Скажем, в рассказе детского писателя Н. Носова «Фантазеры» говорится о двух мальчиках, которые «рассказывали друг другу разные небылицы, будто пошли на спор, кто кого переврет». Но за пределами таких дискурсивных обстоятельств данные глаголы будут оставаться в лучшем случае потенциальными единицами; по этой причине словари их обычно не замечают (Норман 1987: 5-6).

Ту же ситуацию - соперничества или состязания - можно обозначить в русском языке с помощью описательных средств: словосочетаний или целых предложений. Примерами могут служить вопросительные высказывания типа задаваемых детям: У кого руки самые чистые? Кто первым решит задачу? Кто у нас самый сообразительный? Кто дольше не отведет взгляда? и т. п. Соответственно, и номинативное определение ситуации «кто кого» примени- 
тельно к отдельным видам деятельности тоже оказывается расчлененным, составным. В качестве примеров можно привести наименования типа: соревнование по прыжкам в воду, чемпионат по легкой атлетике, конкурс исполнителей, состязание лжецуов и т. п., не имеющие однословных эквивалентов.

Если принимать, что основной, типичной и устойчивой формой существования понятия является слово (а словосочетание составляет ему конкуренцию только при условии своей устойчивости), то придется признать, что в сознании носителя русского языка отсутствуют специальные понятия типа 'состязаться в таком-то виде деятельности'. А соответствующие ситуации объективной действительности отражаются в речемыслительном процессе путем комбинирования понятий (и выражающих их лексических единиц).

В болгарском же языке существует специальная словообразовательная модель со значением состязания в какой-либо деятельности. Важнейшее ее формальное средство - префикс над-, который (как и префикс пере- в русском) является полисемичным. В частности, новейший академический словарь болгарского языка в своем 10-м томе насчитывает у глагольной приставки над4 значения, в том числе «превосходство по отношению к кому-то или чемуто, умение обогнать кого-то в какой-то работе, действии или качестве, сделать что-то лучше, быстрее или в большей степени, чем другой» (РБЕ 2000: 140141). Примерами здесь служат лексемы надбягвам 'бегать быстрее, чем ктото', надвиквам 'перекрикивать, превосходить кого-то в крике', надживявам 'переживать, жить дольше, чем кто-то', надльгвам 'перевирать, превосходить кого-то во вранье', надсвирвам 'играть на музыкальных инструментах лучше или дольше, чем кто-то другой', надхитрявам 'быть хитрее кого-то' и т. д. Все эти болгарские глаголы, естественно, также требуют после себя прямого дополнения, обозначающего субъекта, чья деятельность оказывается «превзойденной». Словарь (РБЕ 2000) включает в себя несколько десятков таких лексем. В работе (Норман 1987: 7-9) мы попытались вскрыть внутриязыковые предпосылки, способствующие грамматикализации данного значения, и выявить фильтры (запреты) на его реализацию.

Но от глаголов со значением 'превосходства' в болгарском языке при помощи возвратной частицы се легко образуются глагольные дериваты со специальной семантикой 'состязания в отдельном виде деятельности'. Приведем примеры из (РБЕ 2000): надвиквам се 'состязаться, меряться силами с кем-то в крике'; надигравам се 'состязаться, соревноваться с кем-то, обычно в танце, пляске'; надмервам се 'состязаться в точности стрельбы'; надтичвам се 'состязаться с кем-то в беге'; надхитрявам се 'соревноваться в хитрости'; надхърквам се 'храпеть сильно, как будто состязаться с кем-нибудь в храпе', надшивам се 'соревноваться в шитье' и т. п.

Механизм этого семантического перехода заключается в том, что возвратная морфема к семе ‘превосходства в какой-то деятельности' прибавляет регулярную сему 'взаимности' (стремления к такому превосходству); в результате и образуется значение 'состязания'. Добавим к этому, что от глаголов несовершенного вида в современном болгарском языке практически без ограничений образуются существительные со значением процесса. Глаголы типа надвиквам ce не составляют в данном плане исключения: словари фиксируют значитель- 
ное количество существительных со значением состязания в конкретном виде деятельности. Примерами могут служить слова надплуване 'состязание в плавании', надпрепускане ‘конные состязания, скачки', надпяване ‘конкурс певцов', надшиване 'соревнование в шитье' и т. д. Таким образом, корневая глагольная морфема порождает целую деривационную цепочку, например: лъжа 'лгать' надльгвам 'превосходить кого-нибудь во лжи' - надльгвам се 'состязаться во вранье' - надльгване 'состязание лжецов'. И каждое звено в этой цепочке образуется с достаточно высокой степенью регулярности.

Мы приходим к выводу, что значение 'состязания в каком-то виде деятельности’ в болгарском языке (по сравнению с русским) сильно грамматикализовано: оно выражается более обязательно и более регулярно (с помощью одних и тех же языковых средств). Своеобразие языковой системы в данном фрагменте означает, что и в сознании носителей болгарского языка подкласс соответствующих понятий вычленяется лучше: данные ситуации более упорядочены и категоризованы.

В то же время, отмечая высокую продуктивность болгарского префикса надсо значением превосходства или состязания, следует отметить, что его семантические и словообразовательные возможности не безграничны. Глаголы и существительные с над- легко образуются для обозначения действий простых, бытовых, «народных» - таких, как жить, жать, кричать, врать, петь, плясать, пить, шить, вязать, бегать, плавать, прыгать, бросать и т.п. Но трудно себе представить контексты, в которых появились бы глаголы вроде надтренирам (се) или надкокетирам (се), существительные вроде надобъркване или надокупиране... В принципе, круг действий, в которых человек готов сравнивать свои возможности и достижения с результатами деятельности других людей, не столь уж широк. В этом заключается семантический «фильтр» на образование подобных лексем и препятствие на пути дальнейшей грамматикализации соответствующей модели. Ограничения могут возникнуть и со стороны морфемной структуры - из-за наличия в лексическом составе болгарского языка слов с омонимичным префиксом (надзиравам, надценявам, надсмивам се и т.п.).

Сопоставление материала близкородственных языков дает множество примеров семантических расхождений, обусловленных типологическими особенностями каждого языка. В. Ф. Васильева, разрабатывающая принципы «семантической характерологии», пишет: «Неодинаковая функциональная нагрузка межъязыковых формально-структурных эквивалентов часто является причиной межъязыковой семантической асимметрии» (Васильева 2003: 8) - и иллюстрирует этот тезис сопоставлением фрагментов словообразовательных систем чешского и русского языков. Тем более существенны расхождения в картинах мира, организуемых неблизкородственными языками. В. Г. Гак, сопоставляя речемыслительную практику носителей французского и русского языков, писал: «Отбор языковых элементов в речи, в процессе организации высказывания... показывает, какие элементы действительности, какие их свойства и отношения имеют приоритетное значение в речевом сознании говорящих на данном языке людей» (Гак 2000: 54). Расхождения обнаруживались в трактовке капитальных феноменов - звука и цвета, местонахождения и обладания, настоящего и ненастоящих времен и т.Д. В частности, если говорить о ситуации движения, то оказывалось, что «при описании одного и того же фрагмента ситуации говорящий 
на французском языке отмечает прежде всего направление данного движения, тогда как говорящий на русском языке - способ передвижения или же способ передвижения вместе с указанием на его направление (префиксальный глагол)» (Там же: 55).

Каждый язык не только выбирает семантические сферы, подлежащие грамматикализации в большей мере, чем другие, но и самостоятельно группирует формальный инструментарий, который должен обеспечить передачу соответствующих значений. В частности, каждый славянский язык «по своему усмотрению» использует с этой целью общеславянский морфемный фонд. Скажем, та же общеславянская морфема *nad (с первоначальным локальным значением) получает своеобразное развитие в польском языке. Среди значений префикса nad- трехтомный Словарь польского языка под ред. М. Шимчака выделяет следующие: «более высокую степень общественной иерархии по отношению к лицам, обозначенным производящим существительным, например: nadburmistrz, nadleśniczy, nadradca»; «превышение нормы, обычного состояния того, что обозначает производящая основа, например: nadciśnienie, nadczłowiek, nadczułość, nadgodzina, nadkwaśny, nadprodukcja, nadwaga, nadrzędny, nadwrażliwy» (SJP II 1998: 231-232).

И тот же словарь фиксирует более 50 существительных с данным префиксом, в толковании которых обнаруживается семантический элемент 'сверх', 'более, чем', 'дополнительно к' и т.п.: nadbagaż, naddruk, nadjaźń, nadkomisarz, nadopiekuńczość, nadprzewodnik, nadużycie и др. Та же сема фиксируется в составе лексического значения прилагательных: naddźwiękowy, nadgorliwy, nadobowiązkowy, nadplanowy, nadspodziewany, nadzmysłowy и т.п., глаголов nadłozyć, nadpłacać, nadużywać и т.д.

Но самое интересное - как эти польские слова переводятся на русский язык. Для проверки мы воспользуемся Польско-русским словарем (Стыпула и др. 1980). Здесь nadbagaż (то же nadwaga) - это перевес (излишний багаж), nadciśnienie - гипертония, nadczłowiek - сверхчеловек, nadczynność - гиперфункция, naddruk - дополнительный тираж, nadfiolet - ультрафиолет, nadgodzina - сверхурочные часы, nadinspektor - старший инспектор, nadkwaśność - повышенная кислотность, nadmietraż - излишек жилой площади, nadprodukcja перепроизводство, nadrealizm - сюрреализм, nadtlenek - перекись, nadużycie - злоупотребление, nadwrażliwość - чрезмерная чувствительность, идиосинкразия, nadwzroczność - дальнозоркость и т. д. На фоне унифицированного, однотипно выражаемого значения «сверхмеры» в польском языке бросается в глаза разнородность средств, используемых в русских эквивалентах. И это различие, очевидно, не случайно: оно свидетельствует о разной степени грамматикализации данного понятия в двух родственных языковых системах.

Вместе с тем, рассуждая о степени грамматикализованности польского префикса nad-, нельзя не заметить, что у него есть конкуренты в словообразовательной системе того же языка - в частности, префикс prze- приблизительно с тем же значением «сверхнормы»: przemoc, przepał, przerost, przewaga, przejrzały, przeokropny, przepiękny, przepyszny, prześwietny, przezabawny и т.п. Это - проявление парадигматической вариативности, сопротивляющееся процессу грамматикализации в данной сфере. 
По К. Леманну, грамматикализация бывает слабая и сильная; правомерно рассматривать их как две стадии единого эволюционного процесса (Lehmann $2002,146)$. Рассмотренные нами два случая (с омонимичными префиксами надв болгарском и nad- в польском) представляют собой, очевидно, как раз промежуточную стадию. Обе морфемы характеризуются сильной степенью связанности и семантической интегрированности с основой, они фиксированы в своем местоположении, но, вместе с тем, не обладают достаточной степенью облигаторности: лексическая база их широка, но не безгранична.

Очевидно, человек не может в равной степени осваивать, семантизировать весь окружающий его мир, с его пространством и временем. Он выбирает из него некоторые островки, узлы, и поручает своему языку упорядочить их, категоризовать. Одним из путей такого упорядочения и является грамматикализация. Среди значений, подвергающихся в славянских языках грамматикализации, - различные виды модальности, фазовость и многократность действия, определенность и неопределенность денотата, его расчлененность или нерасчлененность, уменьшительность или увеличительность по сравнению с некоторым общепринятым стандартом и т.п.

Каждый язык вправе оставить некоторые семантические явления вне сферы действия категоризации - в слабо организованном или даже хаотическом виде. Скажем, сема 'отказаться от действия, прекратить его', представленная в русских глаголах расхотеть, раздумать, разонравиться, раззнакомиться, раздружиться и т.П., ограничивает свое влияние штучным набором единиц (не говорят по-русски «размечтать» 'перестать мечтать' или «разрадоваться» 'перестать радоваться’). Трудно сказать, почему язык выбирает в качестве объекта грамматикализации одни семантические сферы и отвергает другие. Может быть, тут играют роль какие-то культурные или внутриязыковые обстоятельства, но, возможно, мы имеем здесь дело с простой случайностью.

Так, в русском языке XIX века заметную тенденцию к грамматикализации обнаруживало значение многократности (или повторяемости, итеративности) глагольного действия, и основным средством его формального выражения был суффикс -ива- в глаголах несовершенного вида. Словари и грамматики фиксируют в этот период такие образования, как хаживать, сиживать, нашивать, говаривать, читывать, писывать, дельвать, ганивать, обедыввать, игрывать, слыхивать, бегивать, видать (и видывать), знавать, живать, певать, пивать, едать, бивать и др. У И.А. Крылова встречается дирать (от драть), у С.Т. Аксакова - нахаживать (от находить), у М.Е. Салтыкова-Щедрина - лавливать (от ловить) и т.д. Сегодня от этого длинного ряда глаголов в активном употреблении остаются буквально считаные единицы, а сама словообразовательная модель должна быть охарактеризована как потенциальная. В чем причина такой переоценки ценностей?

Возможно, дело в ограниченности парадигмы указанных глаголов: они были неупотребительны в других формах, кроме формы прошедшего времени (см.: Грамматика 1952 I: 489-490). Очевидно, для квалификации действия как многократного человеку необходима была некая ретроспектива событий; это и объясняет склонность итеративных глаголов к претериту. Кстати, следует опять-таки признать, что не так уж много действий, которые сознанием могут восприни- 
маться как повторяющиеся. При этом значимость действия должна соотноситься с временным интервалом. Скажем, Он пишет мне письма каждую неделю - действие повторяющееся и регулярное. Регулярным можно признать и действие в примере Он приезжает ко мне в гости каждый год. Но ситуацию в высказывании Он пишет мне письма раз в 10 лет трудно признать повторяющейся: здесь применяется иной масштаб и временной интервал оказывается слишком велик. (На этом основан эффект известной шутки: Я пью редко, но регулярно - редкое событие не воспринимается как регулярное и даже как повторяющееся.)

Что же касается ситуации с итеративными глаголами в русском языке, то, повидимому, мы являемся свидетелями того, что социум предпочел более однозначный, хотя и менее регулярный способ выражения многократности - с помощью лексических маркеров типа каждый раз, ежедневно, по вечерам, время от времени, регулярно, опять и т.п. В других славянских языках у категории итеративности более счастливая судьба. В частности, в современном чешском она представлена огромным количеством глаголов (jezdívat, chodívat, dělávat, psávat, čitávat, mívat, spávat, vařívat, kupovávat и др.); но и тут нельзя сказать, что процесс грамматикализации достигает своей вершины (Широкова и др. 1990: 197-199).

Освоение фрагмента действительности естественно выражается в его вербализации. Это подразумевает, что когнитивные процессы первичны по отношению к языковым. Но между процессами ментальной категоризации явлений и грамматикализации значений есть и обратная связь. Ее можно сформулировать примерно следующим образом. Чем более грамматично в языке некоторое значение, тем чаще (в синхроническом плане) прибегает к нему носитель языка - то есть тем чаще оно как бы неосознанно приходит в голову говорящему или слушающему.

\section{Использованная литература}

Васева, Иванка. Преизказване. Чужда (неавторска) реч. София: Авангард Прима, 2005.

Васильева, Валерия Ф. «Семантическая характерология в контексте сопоставительного изучения языков (на материале чешского и русского языков)». Вестник Московского университета. Сер. 9. Филология 2, 2003: 7-17.

Виденов, Михаил. Практическа социолингвистика (отговори на актуални езикови въпроси). София: Просвета, 1994.

Гак, Владимир Г. «Язык как форма самовыражения народа». [В:] Язык как средство трансляции культуры. Отв. ред. М. Б. Ешич. Москва: Наука, 2000, 54-68.

Грамматика русского языка. Том I. Фонетика и морфология. Москва: АН СССР, 1952.

Ковш, Ольга А. Вербальные средства выражения недоверия в диалогическом общении (на материале болгарского языка). Автореферат дисс. ... канд. филол. наук. Минск, 2007.

Копотев, Михаил. «Эволюция русских маркеров ренарратива: синтаксис или лексика?» [В:] C.C. Сай и др. (ред.) Acta Linguistica Petropolitana. Труды Института лингвистических исследований. Том X, часть 2. Русский язык: Грамматика конструкций и лексико-семантические подходы. Санкт-Петербург: Наука, 2014, 712-740.

Корнилов, Олег А. Языковые картины мира как производные национальных менталитетов. Изд. 2-е. Москва: ЧеРо, 2003.

Куцаров, Иван. Едно екзотично наклонение на българския глагол. София: Университетско издателство «Св. Климент Охридски», 1994.

Норман, Борис. «О внутриязыковых факторах номинационного процесса (по поводу од-

Славистика XXII/1 (2018) 
ной словообразовательной модели в болгарском языке и ее соответствий в русском)». Съпоставително езикознание XII/4, 1987: 5-9.

Норман, Борис Ю. Болгарский язык в лингвострановедческом аспекте. Курс лекций. Минск: БГУ, 2005.

Ожегов, Сергей И. Словарь русского языка. Изд. 20-е, стереотипное. Москва: Русский язык, 1988.

РБЕ: Речник на българския език. Т. 10, Н. Глав. ред. Е. Пернишка, Л. Крумова-Цветкова. София: Академично издателство «Проф. Марин Дринов», 2000.

Стыпула, Рышард, Ковалева Г. Польско-русский словарь. Около 35000 слов. Москва Варшава: Русский язык - Ведза Повшехна, 1980.

Цивьян, Татьяна В. Модель мира и ее лингвистические основы. Москва: КомКнига, 2005.

Чакърова, Красимира, Костова П. Феноменът стилистична грешка. Пловдив: Марица, 1999.

Широкова, Александра Г., Васильева В. Ф., Едличка А. Чешский язык. Москва: Издательство Московского университета, 1990

Bybee, Joan. "Cognitive Processes in Grammaticalization". [In:] M. Tomasello (ed.) The New Psychology of Language. Cognitive and Functional Approaches to Language Structure. Volume 2. Mahwah, New Jersey - London, 2003, 145-167.

Lehmann, Christian. "Thoughts on Grammaticalization". [In:] Arbeitspapiere des Seminars für Sprachwissenschaft der Universität Erfurt 9, $2002<\mathrm{http} / /$ www.christianlehmann.eu/publ/ ASSidUE09.pdf.> 21.01.2018.

Lehmann, Christian. "Theory and method in grammaticalization". Zeitschrift für Germanistische Linguistik 32/2, 2005: 152-187.

SJP: Słownik Języka Polskiego. Red. naukowy M. Szymczak. T. II. L-P. Warszawa: PWN, 1998.

Борис Норман

\title{
ГРАМАТИКАЛИЗАЦИЈА ЈЕЗИЧКЕ ЈЕДИНИЦЕ И СФЕРА ДЕЛОВАЊА КОГНИТИВНИХ ПРОЦЕСА
}

\author{
Резиме
}

Објекат овог рада чине процеси граматикализације у словенским језицима. Прво се разматра проблем евиденцијалности и његово решење у различитим језицима. Пореде се употреба специјализованих речци мол, дескать, якобы у руским текстовима и облици ренаративног (имперцептивног) начина у бугарском језику. Анализира се конкретни књижевни текст на бугарском језику, који се пореди са преводом потоњег на руски језик, запажа се ретка употреба у преводу специјализованих партикула.

Друга сфера деловања процеса граматикализације је представљена творбеним моделима са значењем надмоћи у некој сфери делатности и одмеравања снага у њој. Продуктивни модел са префиксом над- у бугарском језику је заступљен глаголима попут надпявам (се), надвиквам (се), надплитам (се), надльгвам (се), који због своје граматикализованости немају потпуне аналоге у руском језику, већ се њихово значење преноси описно.

Други префикс nad-, који можемо сматрати хомонимом оног раније поменутог, регуларно се користи у другом словенском језику - пољском, са циљем указивања на значење „преко норме“, „сувише“, „допунски“: naddruk, nadinspektor, nadgodzina, nadplanowy, nadzmystowy итд. Осим тога, ниједна од поменутих појава се не може сматрати потпуно граматикализованом јер не садржи све одговарајуће показатеље (према К. Леману).

У раду се разматрају и друге чињенице из словенске граматике, попут итеративних глагола у руском и чешком језику. Формулише се претпоставка о факторима који утичу на ток граматикализације. Сваки од језика бира из екстралингвистичке стварности одређене сми- 
саоне чворове и категоризује их на свој начин. Један од путева такве систематизације је граматикализација. Ипак неке семантичке појаве могу остати ван сфере категоризације, у слабо организованом па чак и хаотичном облику.

На крају рада дат је општи закључак о повезаности категоризације са граматикализацијом језичких чињеница. Формулише се теза о повратној спрези између менталних и језичких механизама: што је више граматично у језику одређено значење, то га чешће (са синхронијског аспекта) користи носилац језика, те оно природније пада на памет говорном лицу и слушаоцу.

Кључне речи: граматикализација, словенски језици, творбени модел, префикс, когнитивна сфера, категоризација. 